\title{
Hot-Melt Extrusion (HME): From Process to Pharmaceutical Applications
}

\author{
Mohammed Maniruzzaman, Dennis Douroumis, \\ Joshua S. Boateng and Martin J. Snowden
}

Additional information is available at the end of the chapter

http://dx.doi.org/10.5772/51582

\section{Introduction}

Over the last three decades hot-melt extrusion (HME) has emerged as an influential processing technology in developing molecular dispersions of active pharmaceutical ingredients (APIs) into polymers matrices and has already been demonstrated to provide time controlled, modified, extended and targeted drug delivery resulting in improved bioavailability [1, 2, 3, 4]. HME has now provided opportunity for use of materials in order to mask the bitter taste of active substances. Since industrial application of the extrusion process back in the 1930's HME has received considerable attention from both the pharmaceutical industry and academia in a range of applications for pharmaceutical dosage forms, such as tablets, capsules, films and implants for drug delivery through oral, transdermal and transmucosal routes [5]. This makes HME an excellent alternative to other conventionally available techniques such as roll spinning and spray drying. In addition to being a proven manufacturing process, HME meets the goal of the US Food and Drug Administration's (FDA) process analytical technology (PAT) scheme for designing, analyzing as well as controlling the manufacturing process through quality control measurements during active extrusion process [6]. In this chapter we review the hot-melt extrusion technique, based on a holistic perspective of its various components, processing technologies as well as the materials and novel formulation design and developments to its varied applications in oral drug delivery systems.

\section{Hot-melt extrusion (HME): Process technology}

Joseph Brama first invented the extrusion process for the manufacturing of lead pipes at the end of the eighteenth century [7]. Since then, it has been used in the plastic, rubber and food manufacturing industries to produce items ranging from pipes to sheets and bags. With the 
advent of high throughput screening, currently more than half of all plastic products including bags, sheets, and pipes are manufactured my HME and therefore various polymers have been used to melt and form different shapes for a variety of industrial and domestic applications. The technology (HME) has proven to be a robust method of producing numerous drug delivery systems and therefore it has been found to be useful in the pharmaceutical industry as well [8]. Extrusion is the process of pumping raw materials at elevated controlled temperature and pressure through a heated barrel into a product of uniform shape and density [9]. Breitenbach first introduced the development of melt extrusion process in pharmaceutical manufacturing operations [10], however, Follonier and his co-workers first examined the hot melt technology to manufacture sustained release polymer based pellets of various freely soluble drugs [11]. HME involves the compaction and conversion of blends from a powder or a granular mix into a product of uniform shape [9]. During this process, polymers are melted and formed into products of different shapes and sizes such as plastic bags, sheets, and pipes by forcing polymeric components and active substances including any additives or plasticisers through an orifice or die under controlled temperature, pressure, feeding rate and screw speed [9, 12]. However, the theoretical approach to understanding the melt extrusion process could be summarized by classifying the whole procedure of HME compaction into the followings [13]:

1. Feeding of the extruder through a hopper

2. Mixing, grinding, reducing the particle size, venting and kneading

3. Flow through the die.

4. Extrusion from the die and further down-stream processing.

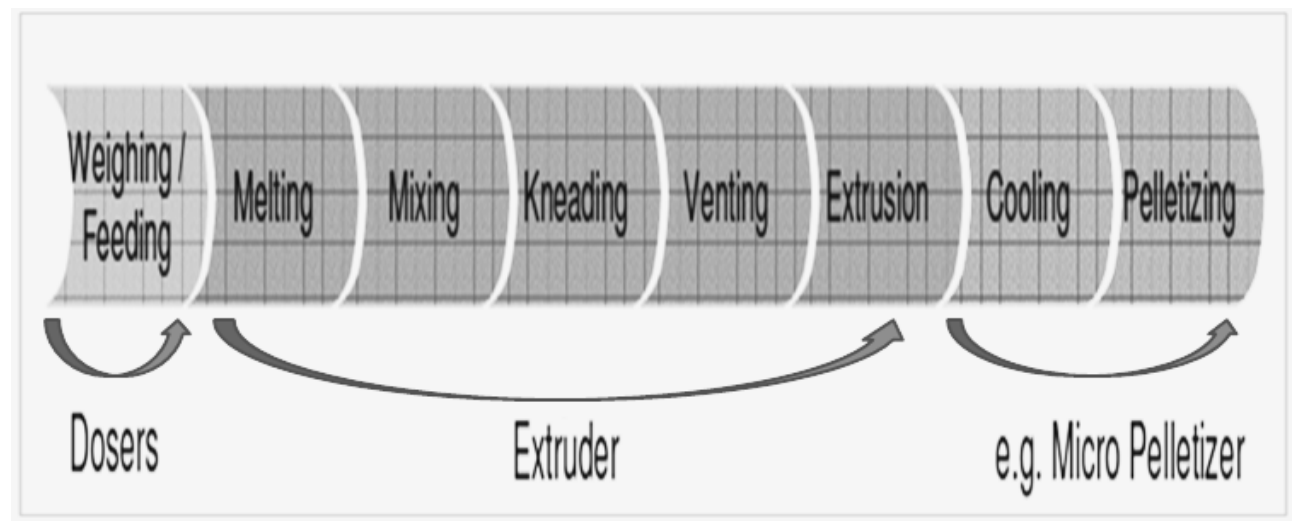

Figure 1. Schematic diagram of HME process [12].

The extruder generally consists of one or two rotating screws (either co-rotating or counter rotating) inside a stationary cylindrical barrel. The barrel is often manufactured in sections in order to shorten the residence time of molten materials. The sectioned parts of the barrel are then bolted or clamped together. An end-plate die is connected to the end of the barrel which is determined according to the shape of the extruded materials. 


\section{Equipment: Single screw and twin screw extruder}

A single screw extruder consists of one rotating screw positioned inside a stationary barrel at the most fundamental level. In the more advanced twin-screw systems, extrusion of materials is performed by either a co-rotating or counter-rotating screw configuration [9]. Irrespective of type and complexity of the function and process, the extruder must be capable of rotating the screw at a selected predetermined speed while compensating for the torque and shear generated from both the material being extruded and the screws being used. However, regardless of the size and type of the screw inside the stationary barrel a typical extrusion set up consists of- a motor which acts as a drive unit, an extrusion barrel, a rotating screw and an extrusion die [13]. A central electronic control unit is connected to the extrusion unit in order to control the process parameters such as screw speed, temperature and therefore pressure [14]. This electronic control unit acts as a monitoring device as well. The typical length diameter ratios $(\mathrm{L} / \mathrm{D})$ of screws positioned inside the stationary barrel are another important characteristic to consider whether the extrusion equipment is a single screw or twin screw extruder. The L/D of the screw either in a single screw extruder or a twin screw extruder typically ranges from 20 to $40: 1(\mathrm{~mm})$. In case of the application of pilot plant extruders the diameters of the screws significantly ranges from 18-30 $\mathrm{mm}$. In pharmaceutical scale up, the production machines are much larger with diameters typically exceeding 50-60mm [15]. In addition, the dimensions of a screw change over the length of the barrel. In the most advanced processing equipment for extrusion, the screws could be separated by clamps or be extended in proportion to the length of the barrel itself. A basic single screw extruder consists of three discrete zones: feed zone, compression and a metering zone (Fig. 2). Under the compression zone which is basically know as processing zone could be accompanied by few other steps such as mixing, kneading, venting etc [13, 15].

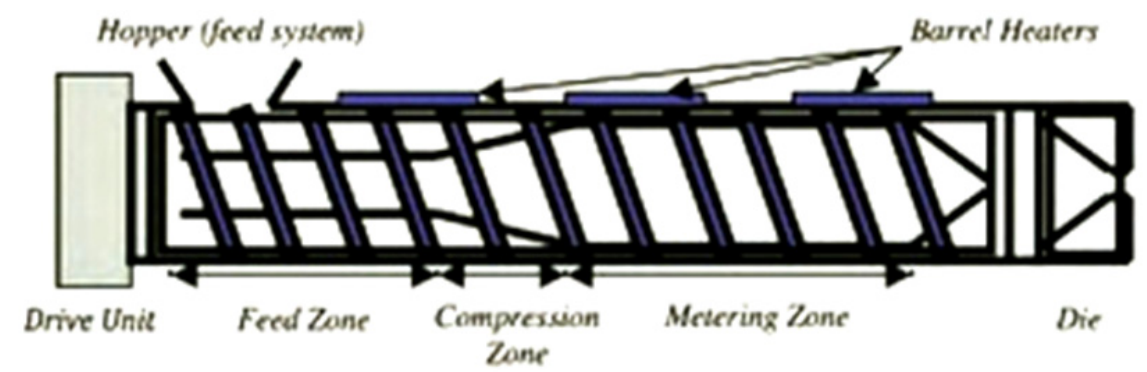

Figure 2. Schematic diagram of a single screw extruder [10].

The depth along with the pitch of the screw flights (both perpendicular and axial) differ within each zone, generating dissimilar pressures along the screw length (Fig. 3). Normally the pressure within the feed zone is very low in order to allow for consistent feeding from the hopper and gentle mixing of API, polymers and other excipients and therefore the screw flight depth and pitch are kept larger than that of other zones. At this stage of the process the pressure within the extruder is very low which subsequently gets increased in the 
compression zone. This results in a gradual increase in pressure along the length of the compression zone which effectively imparts a high degree of mixing and compression to the material by decreasing the screw pitch and/or the flight depth ${ }^{[9,15]}$. Moreover the major aim of the compression zone is not only to homogenize but also compress the extrudate to ensure the molten material reaches the final section of the barrel (metering zone) in a form appropriate for processing. Finally the final section which is known as the metering zone stabilizes the effervescent flow of the matrix and ensures the extruded product has a uniform thickness, shape and size. A constant and steady uniform screw flight depth and pitch helps maintain continuous high pressure ensuring a uniform delivery rate of extrudates through the extrusion die and hence a uniform extruded product.

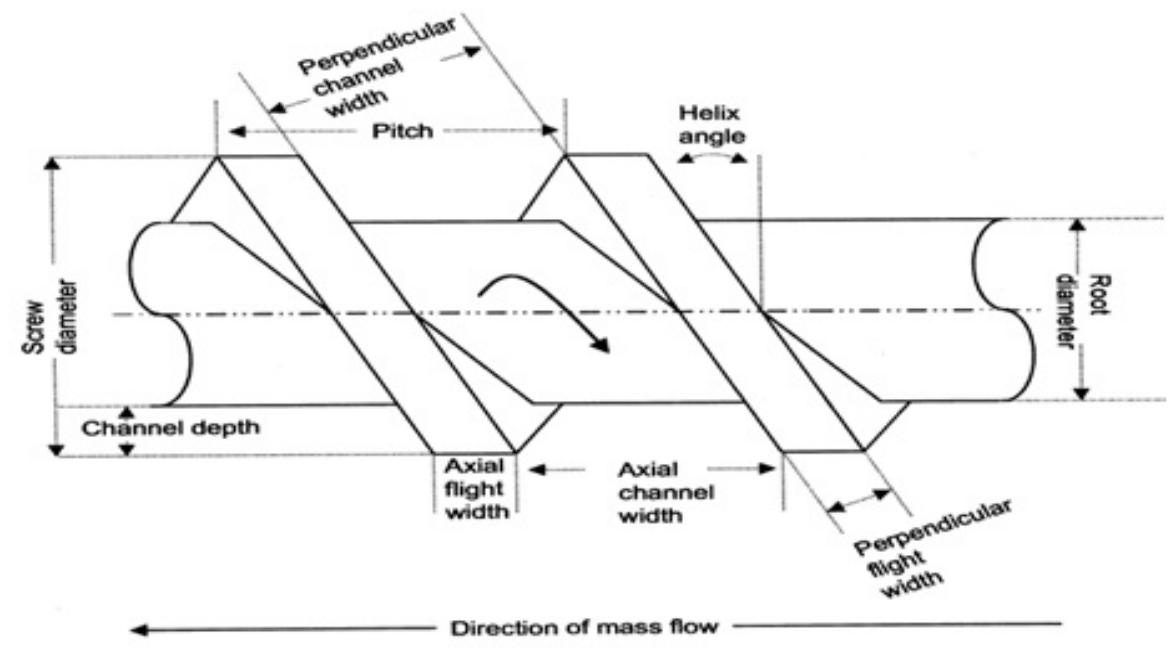

Figure 3. Screw geometry (extrusion) [9].

In addition to the above mentioned systems, downstream auxiliary equipment for cooling, cutting, collecting the finished product is also typically employed. Mass flow feeders to accurately meter materials into the feed hopper, pelletizers, spheronizer, roller/calendaring device in order to produce continuous films and process analytical technology such as near infra-red (NIR) and Raman, ultra sound, DSC systems are also options. Throughout the whole process, the temperature in all zones are normally controlled by electrical heating bands and monitored by thermocouples.

The single screw extrusion system is simple and offers lots of advantages but still does not acquire the mixing capability of a twin-screw machine and therefore is not the preferred approach for the production of most pharmaceutical formulations. Moreover, a twin-screw extruder offers much greater versatility (process manipulation and optimisation) in accommodating a wider range of pharmaceutical formulations making this set-up much more constructive. The rotation of the screws inside the extruder barrel may either be corotating (same direction) or counter-rotating (opposite direction), both directions being 
equivalent from a processing perspective. A greater degree of conveying and much shorter residence times are achievable with an intermeshing set-up. Furthermore, the use of reverseconveying and forward-conveying elements, kneading blocks and other intricate designs as a means of improving or controlling the level of mixing required can help the configuration of the screws themselves to be varied [16].
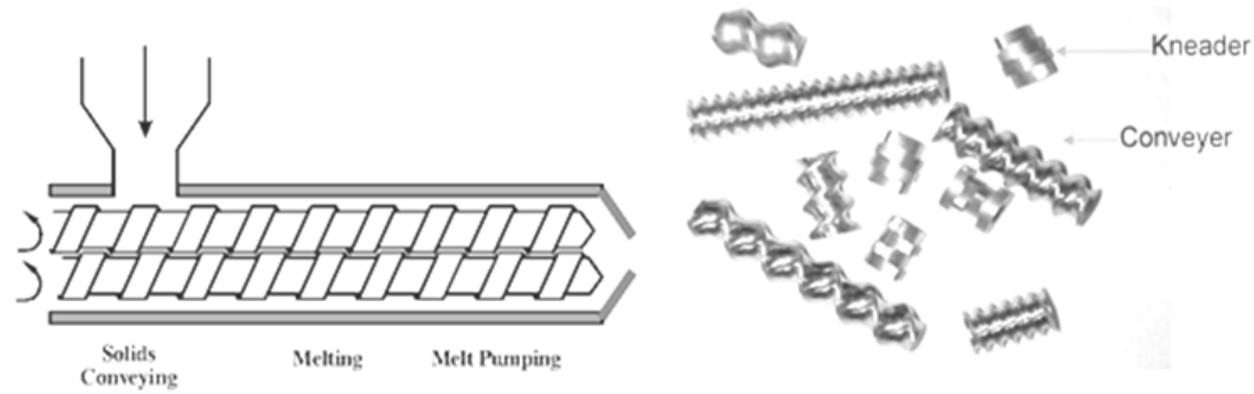

Figure 4. A twin screw extruder and screws [9].

\section{Advantages of HME}

HME offers several advantages over conventionally available pharmaceutical processing techniques including: (a) increased solubility and bioavailability of water insoluble compounds, (b) solvent free non ambient process, (c) economical process with reduced production time, fewer processing steps, and a continuous operation, (d) capabilities of sustained, modified and targeted release, (e) better content uniformity in extrudates, (f) no requirements on the compressibility of active ingredients, (g) uniform dispersion of fine particles, (h) good stability at changing $\mathrm{pH}$ and moisture levels and safe application in humans, (i) reduced number of unit operations and production of a wide range of performance dosage forms, and (j) a range of screw geometries [17, 18, 19, 20, 21].

However, HME has some disadvantages as well. The main drawbacks of HME include: thermal process (drug/polymer stability), limited polymers, high flow properties of polymers and excipients required and not suitable for relatively high heat sensitive molecules such as microbial species, proteins etc [20, 21].

\section{Applications of HME}

Extrusion technology is one of the most important fabrication processes in the plastic and rubber industries. Products made from melt extruded polymers range from pipes to hoses through to the insulated wires, cables, rubber sheeting and polystyrene tiles. Plastics that are commonly processed by HME technique include acrylics and cellulosics, polyethylene, poly propylene, polystyrene and vinyl plastics $[9,22]$. In the food industry, extrusion has been utilized for pasta production with a widely used multitalented technique combines cooking and extrusion in a self-styled extrusion cooker [23]. In the animal feed industry and veterinary science, extrusion is commonly applied as a means of producing pelletized feeds, 
implants or injection moulding [24]. HME has successfully been applied in the formulation of fast dispersing PVP melt extrudates of poorly soluble active agents as solid molecular dispersions in the crop protection field [25].

HME technology has already achieved a strong place in the pharmaceutical industry and academia due to several advantages over traditional processing methods such as roll spinning, grinding [18]. In addition to being an efficient manufacturing process, HME enhances the quality and efficacy of manufactured products and therefore over the past few years HME has emerged as a novel technique in the pharmaceutical applications [15, 28]. The main use of HME is to disperse active pharmaceutical ingredients (APIs) in a matrix at the molecular level, thus forming solid solutions [26]. In the pharmaceutical industry, HME has been used for various applications, such as i) enhancing the dissolution rate and bioavailability of poorly soluble drug by forming a solid dispersion or solid solution, ii) controlling or modifying the release of the drug, iii) taste masking of bitter APIs, and iv) formulation of various thin films [27].

The bioavailability of an active ingredient is controlled by its aqueous solubility. Therefore increasing the solubility of water insoluble drugs is still a real challenge in the formulation development process [26]. Due to the advent of high throughput screening (HTS) in the drug discovery process, the resultant compounds are often high molecular weight and highly lipophilic and therefore exhibit poor solubility [29]. Scientists have already tried to address solubility issues by various pharmaceutical interventions. Among the many methods available to improve solubility and dissolution rate, preparation of solid dispersions and solid solutions has gained vast attention. For that reason HME has been successfully applied to prepare solid molecular dispersion of APIs into different hydrophilic polymer matrices [26, 29].

\section{Formulation research and developments to dates}

Despite the fact that initial research developments have focused on the effects of formulation and processing variables on the properties of the final dosage forms, $[9,30,31$, $34,35]$ more recent investigations have focused on the use of HME as a novel manufacturing technology of solid molecular dispersions through to the development of mini-matrices, taste masked formulations and also sustained release formulations as well as paediatric formulations [26, 48]. Early work by De Brabander et al. (2000) described the preparation of matrix mini-tablets which was followed by further investigations into the properties of sustained release mini-matrices manufactured from ethyl cellulose, HPMC and ibuprofen $[32,33]$. Extruded mini tablets showed minimised risk of dose dumping, reduced inter- and intra-subject variability. Very recently, Roblegg et al. (2011) reported the development of retarded release pellets using vegetable calcium stearate (CaSt) as a thermoplastic excipient processed through HME, where pellets with a drug loading of $20 \%$ paracetamol released only $11.54 \%$ of the drug after 8 hours due to the significant densification of the pellets. As expected, the drug release was influenced by the pellet size and the drug loading [36]. A microbicide intravaginal ring (IVRs) IVR was prepared and developed from polyether 
urethane (PU) elastomers for the sustained delivery of UC781 (a highly potent nonnucleoside reverse transcriptase inhibitor of HIV-1). PU IVRs containing UC781 were fabricated using a hot-melt extrusion process [37].

Moreover, a fourfold increase in the availability of propanolol in the systemic circulation was observed when the HME formulation was compared with a commercially available formulation (Inderal ${ }^{\circledR}$ ). Over the last five years HME has been used largely to manufacture granules, pellets, immediate and modified release tablets, transmucosal/ transdermal films and implantable reservoir devices [3, 4, 9,35]. For instance, with respect to drug administration through the oral route, molecular solid dispersions of nifedipine [38], nimodipine [29] and itraconazole [39, 40,41] have been successfully produced using HME technology. Amorphous indomethacin dispersions have been manufactured using pharmaceutically acceptable hydrophilic polymers by using HME technology [26, 42,43].

Furthermore, HME research developments have driven targeted drug delivery systems including enteric matrix tablets and capsule systems over the last few years [44, 45]. Miller et al. (2007) have demonstrated the ability of HME to act as an efficient dispersive process for aggregated, fine engineering particles to improve dissolution rate properties by enhancing particles' wettability [46]. A very interesting investigation of Verreck and co-workers (2006) [47] determined the use of supercritical carbon dioxide $(\mathrm{scCO} 2)$ as a temporary plasticiser during the manufacture of ethylcellulose through HME. A significant reduction in the processing temperature was achieved using scCO2 without any disadvantageous effects on the extrudate. Macroscopic morphology was significantly altered due to expansion of the $\mathrm{scCO} 2$ in the die. The use of scCO2 increased the surface area, porosity and hygroscopicity of the final dosage forms. More recently Douroumis and co-workers used HME technique to effectively enhance the solubility of ibuprofen, indomethacin and famotidine [26, 42].

The taste masking of bitter APIs is a major challenge especially for the development of orally disintegrating tablets (ODT). HME has been reported to be an effective technique to mask the bitter tastes of various APIs by the use of taste masking polymers that create solid dispersions to prevent bitter drugs from coming in contact with the patient's taste buds. Breitkruitz et al. (2008) successfully applied HME in taste masking of sodium benzoate for the formulation of paediatric drugs [48]. More recently Grycze et al. (2011) and Maniruzzaman et al. (2012) developed taste masked formulations of ibuprofen and paracetamol, respectively [26, 48]. Basically taste masking is achieved through intermolecular forces (e.g. hydrogen bonding) between the active substance and the polymer matrix by processing oppositely charged compounds through HME $[49,50]$. The extrusion of solid lipids using twin-screw extruders was introduced for the preparation of immediate or sustained release taste masked matrices [51]. In this process, occasionally called "solvent - free cold extrusion" the lipids are extruded below their melting ranges. Consequently, the lipids are not melted during extrusion and build a coherent matrix with low porosity. In these few studies the effect of lipid composition and processing parameters such as the die diameter, the size of the extruded pellets, the screw speed and the powder feeding rates on the obtained drug release patterns were thoroughly investigated. Very 
recently, Breitkreutz et al. (2012) applied solid lipid extrusion at room temperature for the taste masked formulation development of the BCS Class II drug NXP 1210. In this study, the authors investigated powdered hard fat (Witocan ${ }^{\circledR} 42 / 44$ mikrofein), glycerol distearate (Precirol® ato 5) and glycerol trimyristate (Dynasan ${ }^{\circledR} 114$ ) as lipid binders. The lipid based formulations design in this study was feasible for taste-masked granules or pellets containing poorly soluble drugs [52].

\subsection{Films by hot-melt extrusion}

Only a handful of researchers have reported the use of hot-melt extrusion for the manufacture of films. Films can be defined as thin sheets containing one or more polymers with or without a plasticiser and may be used as a drug delivery system (device) or directly applied to facilitate a therapeutic effect as in wound dressings. Films are currently being produced mainly by solvent casting in which polymers (and excipients such as plasticisers) are dissolved in a suitable solvent until they form clear viscous solution (gel). While film preparation using the solvent-casting approach allows film uniformity, clarity, flexibility and adjustable thickness to accommodate drug loadings they are limited by decreased elongation or elasticity and increased film tensile strength when physical aging is applied [53]. Another, limitation associated with solvent cast films is the use of organic solvents for water insoluble polymers. The hazardous nature of most organic solvents and the residual solvents after drying affect the selection of the appropriate solvent [54-57] as well as complicated processing conditions and disposal of the associated waste, all of which create significant environmental concerns. As a result, alternative technologies are needed in the pharmaceutical industry to overcome some of challenges described above. The two commonly used approaches include spray coating and hot melt extrusion with the latter becoming increasingly popular due to the many advantages it provides. Firstly, no solvents are used and fewer processing steps are required. In fact one of the key advantages of HME is the fact that extrudates can be obtained in a single processing step making it very economical. As far as films are concerned, there is no requirement for compressing of the active ingredients together with the excipients. The melting of the polymer into the molten state, coupled with the thorough initial mixing allows a more uniform dispersion of fine particles. Further, molecular dispersion of the drug helps improve its bioavailability [58]. Hot melt extruded films are produced through a simple process involving blending of appropriate amounts relevant polymer, drug and plasticiser into a uniform powdered mixture prior to feeding through the hopper of the preheated extruder and transferred into the heated barrel by a rotating extruder screw. Homogeneous films are obtained with thickness generally expected to be in the range less than $1 \mathrm{~mm}$. Generally three main ingredients are required for successful formulation of hot melt films i.e. film forming polymer, active ingredient and plasticiser [59]. The latter is required to impart flexibility to the final film which ensures ease of handling and application to the site of action. Occasionally, other additives are added to affect other functionally important properties such as bioadhesive agent which ensures that the film adheres to the mucosal surface for a long enough time to allow drug absorption or action. Different polymers and drugs have been employed and reported in the literature for obtaining drug loaded hotmelt extruded films for various indications and are summarised in table 1. 


\begin{tabular}{|l|l|l|l|l|}
\hline Film & Main polymer(s) & Plasticiser/additive & $\begin{array}{l}\text { Main active } \\
\text { ingredient(s) }\end{array}$ & $\begin{array}{l}\text { Autho } \\
\text { r }\end{array}$ \\
\hline 1 & $\begin{array}{l}\text { Acrylic } \\
\text { Eudragit }\end{array}$ & $\begin{array}{l}- \text { Triacetin } \\
- \text { Triethylcitrate }\end{array}$ & Lidocaine & {$[60]$} \\
\hline 2 & $\begin{array}{l}\text { Hydroxypropylcellulose } \\
\text { Polyethylene oxide }\end{array}$ & N/A & Ketoconazole & {$[61]$} \\
\hline 3 & $\begin{array}{l}\text { Hydroxypropylcellulose } \\
\text { Hydroxypropylmethylce } \\
\text { llulose } \\
\text { Polyethylene oxide }\end{array}$ & $\begin{array}{l}\text { Polyethylene glycol } \\
3350\end{array}$ & Lidocaine & {$[62]$} \\
\hline 4 & $\begin{array}{l}\text { Hydroxypropylcellulose } \\
\text { Polyethylene glycol } \\
400\end{array}$ & $\begin{array}{l}\text { Hydrocortisone } \\
\text { Polyethylene glycol } \\
\text { Polycarbophil }\end{array}$ & Clotrimazole & {$[65]$} \\
\hline 6 & Polyethylene oxide & N/A & Ketoprofen & {$[59]$} \\
\hline
\end{tabular}

Table 1. Different hot-melt extruded films comprising different polymeric materials, plasticisers and active ingredients for various indications.

Repka and co-workers have conducted extensive research on the use of HME for the manufacture of mucoadhesive buccal films. They successfully evaluated different matrix formers and additives for the processing of the blend prior to extrusion [61, 62, 63, 64]. In an early investigation, it was found that even though films containing exclusively HPC could not be obtained, the addition of plasticizers, such as triethyl citrate, PEG 2000/8000, or acetyltributyl citrate, allowed for the manufacture of thin, flexible, and stable HPC films [65]. It has also been found that increasing the molecular weight of HPC decreased the release of drugs from hot-melt extruded films which resulted in dissolution profiles exhibiting zeroorder drug release. According to the models applied in the research, the drug release was solely determined by erosion of the buccal film $[66,67,68]$.

Development of films by HME may present future opportunities to develop gastro-retentive films for prolonged drug delivery and multi-layer films to modulate drug release for oral and transdermal applications. The growing market in medical devices, including incorporating drugs such as biodegradable stents and drug-loaded catheters will undoubtedly require HME manufacturing processes. These are required to be commercialised and perhaps may lead to new areas of collaboration across pharmaceutical, medical device and biotechnology research.

\section{HME in commercial products}

HME related patents which have been issued for pharmaceutical systems have steadily increased since the early 1980's. So far, the USA and Germany hold approximately more than half (56\%) of all issued patents for HME in the market [69]. Despite this increased interest, only a handful of commercialized HME pharmaceutical products are currently 
marketed. Several companies have been recognized to specialize in the use of HME as a drug delivery technology, such as PharmaForm and SOLIQS (Abbott). Recently, SOLIQS has developed a proprietary formulation which is known as Meltrex® and re-developed a protease-inhibitor combination product, Kaletra ${ }^{\circledR}$. Kaletra is mainly used for the treatment of human immunodeficiency virus (HIV) infections. The formulated, melt extruded product was shown to have a significant enhancement in the bioavailability of active substances [70]. Furthermore, HME Kaletra ${ }^{\circledR}$ tablets were shown to have significant advantages for patient compliance (i.e. reduced dosing frequency and improved stability) compared to the previous soft-gel capsule formulation as recognized by the FDA decision to fast-track approval. Additionally, Nurofen (Meltlets ${ }^{\circledR}$ lemon) is available on the market as a fast dissolving tablet prepared by HME [42]. Ibuprofen has been used as active substance in the Meltlets ${ }^{\circledR}$ tablets where its bitter taste was successfully masked by similar technique to HME. Moreover, SOLIQS has also developed a fast-onset ibuprofen system and a sustainedrelease formulation of verapamil (Isoptin ${ }^{\circledR}$ SR-E) through a HME related technology called 'Calendaring' that was the first directly shaped HME product on the market.

\section{Summary}

HME has proven to be a robust method of producing numerous drug delivery systems and therefore it has been found to be useful in the pharmaceutical industry enlarging the scope to include a range of polymers and APIs that can be processed with or without plasticizers. It has also been documented that HME is a solvent-free, robust, quick and economy favoured manufacturing process for the production of a large variety of pharmaceutical dosage forms.

\section{Author details}

Mohammed Maniruzzaman *, Dennis Douroumis, Joshua S. Boateng and Martin J. Snowden School of Science, University of Greenwich, Central Avenue, Chatham Maritime, Chatham, Kent, ME4 4TB, UK

\section{References}

[1] Maniruzzaman M, Boateng JS, Bonnefille M, Aranyos A, Mitchell JC, Douroumis D. Taste Masking of Paracetamol by Hot Melt Extrusion: an in vitro and in vivo evaluation. Euro J Pharm Biopharm 2012;80(2):433-42.

[2] Repka MA, Shah S, Lu J, Maddineni S, Morott J, Patwardhan K, Mohammed NN. Melt extrusion: process to product. Expert Opin Drug Deliv 2012; 9(1):105-25.

[3] Repka MA, Majumdar S, Kumar Battu S, Srirangam R, Upadhye SB. Applications of hot-melt extrusion for drug delivery. Expert Opin Drug Deliv 2008; 5(12):1357-76.

\footnotetext{
${ }^{*}$ Corresponding Author
} 
[4] Repka MA, Battu SK, Upadhye SB, Thumma S, Crowley MM, Zhang F, Martin C, McGinity JW. Pharmaceutical applications of hot-melt extrusion: Part II. Drug Dev Ind Pharm 2007; (10):1043-57.

[5] Crowley MM, Thumma S, Updhye SB. Pharmaceutical applications of hot melt extrusion: part-1. Drug Dev Ind Pharm 2007; 33(9):909-26.

[6] Charlie M. Continuous mixing of solid dosage forms via Hot-Melt Extrusion. Pharm Tech 2008; 32(10):76-86.

[7] James S. Encyclopedia of Pharmaceutical Technology. 2004; 3rd Ed (3); P-20.

[8] Andrews GP and Jones DS. Formulation and Characterization of Hot Melt Extruded Dosage Forms: Challenges and Opportunities. Cheminform 2010; 41(43).

[9] Breitenbach J. Melt extrusion: from process to drug delivery technology. Eur J Pharm and Biopharm 2002 54:107-117.

[10] Andrews GP, David S, Osama AM, Daniel NM, Mark.S. Hot Melt Extrusion: An Emerging Drug Delivery Technology. Pharm Tech Europe 2009; 21 (1):24-27.

[11] Follonier N, Doelker E, Cole ET. Evaluation of hot-melt extrusion as a new technique for the production of polymerbased pellets for sustained release capsules containing high loadings of freely soluble drugs. Drug Dev Ind Pharm 1994; 20(8):1323-133.

[12] Gryczke A. Melt Extrusion with EUDRAGIT® Solubility Enhancement Modified Release. Degussa. RÖHM GmbH \& Co. KG, Darmstadt. 2006-06-13.

[13] Chokshi R, Zia H. Hot-Melt Extrusion Technique: A Review. Iranian J of Pharm Res 2004; 3: 3-16.

[14] Whelan T, Dunning D (Eds.). The Dynisco Extrusion Processors Handbook 1st ed., London School of Polymer Technology 1988, Polytechnic of North London, London.

[15] Andrews GP, Margetson DN, Jones DS, McAllister SM, Diak OA. A basic Guide: Hotmelt Extrusion. UKICRS 2008; Vol.13.

[16] White JL. Twin Screw Extrusion: Technology and Principles Hanser/ Gardner Publications Inc. 1991; Cincinnati, Ohio. ISBN 1-56990-109-0.

[17] http://www.pharinfo.net/reviews/melt granulation techniques/reviews.

[18] McGnity JW, KOleng JJ. Preparation and Evaluation of Rapid Release Granules Using Novel Melt Extrusion Technique. AAPS.org.2004; 153-54.

[19] Jones DS. Engineering Drug Delivery Using Polymer Extrusion/Injection Moulding Technologies. School of Pharmacy, Queen's University, Belfast: 2008; 4-9, 18, 25, 27.

[20] Grunhagen HH, Muller O. Melt extrusion technology. Pharm. Manu. Int.1995 1, 167170.

[21] Singhal S, Lohar VK, Arora V. Hot-melt extrusion technique. WebmedCentral Pharmaceutical Sciences 2011;2(1): 001459

[22] Mollan M. Historical overview, in: I. Ghebre-Sellassie, C. Martin (Eds.), Pharmaceutical Extrusion Technology, CRC Press 2003; pp. 1-18.

[23] Senouci A, Smith A, Richmond A. Extrusion cooking, Chem. Eng. 417 (1985) 30-33.

[24] Sebestyen E. Flour and animal feed milling 1974; 10;24-25.

[25] Wedlock DJ, Wijngaarden DV. Fast dispersing solid PVP-containing crop protection formulation and process therefore, US Patent 1992; 5,665,369. 
[26] Maniruzzaman M, Rana M, Boateng JS, Douroumis D. Dissolution enhancement of indomethacin and famotidine processed by hot-melt extrusion. Drug developments and Ind Pharmacy 2012; In press.

[27] Morales JO, McConville JT. Manufacture and characterization of mucoadhesive buccal films. European Journal of Pharmaceutics and Biopharmaceutics 2011; 77;187-199.

[28] M. Repka, M. Munjal, M. ElSohly, S. Ross. Temperature stability and bioadhesive properties of D9-tetrahydrocannabinol incorporated hydroxypropylcellulose polymer matrix systems, Drug Development and Industrial Pharmacy 2006; 32: 21-32.

[29] Zheng X, Yang R, Tang X and Zheng L. Part I: Characterization of Solid Dispersions of Nimodipine Prepared by Hot-melt Extrusion. Drug Development and Industrial Pharmacy 2007; 33:791-802.

[30] M.A. Repka, S.K. Battu, S.B. Upadhye, S. Thumma, M.M. Crowley, F. Zhang, C. Martin, J.W. McGinity, Pharmaceutical applications of hot-melt extrusion: Part II, Drug Development and Industrial Pharmacy 2007; 33:1043-1057.

[31] Cilurzo F, Cupone I, Minghetti P, Selmin F, Montanari L. Fast dissolving films made of maltodextrins, European Journal of Pharmaceutics and Biopharmaceutics 2008; 70: 895-900.

[32] De Brabander C, Vervaet C, Fiermans L, Remon JP. Matrix mini-tablets based on starch/microcrystalline wax mixtures. Int J Pharm 2000; 199: 195-203.

[33] De Brabander C, Vervaet C, Remon JP. Development and evaluation of sustained release mini-matrices prepared via hot melt extrusion. J Cont Rel 2003; 89: 235-247.

[34] Zhang F, McGinity JW. Properties of sustained-release tablets prepared by hot-melt extrusion. Pharmaceut Dev Tech 1999; 4(2), 241-250.

[35] Crowley MM, Zhang F, Koleng JJ, McGinity JW. Stability of polyethylene oxide in matrix tablets prepared by hot-melt extrusion. Biomaterials 2002; 23: 4241-4248.

[36] Roblegg E, Jäger E, Hodzic A, Koscher G, Mohr S, Zimmer A, Khinast J. Development of sustained-release lipophilic calcium stearate pellets via hot melt extrusion. Eur Jl Pharms and Biopharms 2011; 79:635-645.

[37] Clark MR, Johnson TJ, McCabe RT, Clark JT, Tuitupou A, Elgendy H, Friend DR, Kiser PF. A hot-melt extruded intravaginal ring for the sustained delivery of the antiretroviral microbicide UC781.J Pharm Sci 2011. In Press

[38] Li L, AbuBaker O, Shao Z, (2006). Characterization of poly(ethylene oxide) as a drug carrier in hot-melt extrusion. Drug Dev Ind Pharm 2006; 32: 991-1002.

[39] Rambali B, Verreck G, Baert L, Massart DL. Itraconazole formulation studies of the melt-extrusion process with mixture design. Drug Dev Pharm 2003; 29(6): 641-652.

[40] Six K, Berghmans H, Leuner C, Dressman J, Van Werde K, Mullens J, Benoist L, Thimon M, Meublat L, Verreck G, Peeters J, Brewster M, Van den Mooter G. Characterization of solid dispersions of itraconazole and hydroxypropylmethylcellulose prepared by melt extrusion, Part II. Pharm Res 2003; 20(7): 1047-1054.

[41] Six K, Daems T, de Hoon J, Van Hecken A, Depre M, Bouche MP, Prinsen P, Verreck G, Peeters J, Brewster ME, Van den Mooter G. Clinical study of solid dispersions of itraconazole prepared by hot-stage extrusion. Eur J Pharm Sci 2005; 24(2-3): 179-186. 
[42] Grycze A, Schminke GS, Maniruzzaman M, Beck J, Douroumis D. Development and evaluation of orally disintegrating tablets (ODTs) containing ibuprofen granules prepared by hot melt extrusion. Colloids Surf B Biointerface 2011; 86: pp. 275-84.

[43] Chokshi RJ, Shah NHS, Sandhu KH, Malick AW, Zia H. Stabilization of Low Glass Transition Temperature Indomethacin Formulations: Impact of Polymer-Type and Its Concentration. Journal of Pharmaceutical Sciences 2007, Published online in Wiley InterScience (www.interscience.wiley.com). DOI 10.1002 jps.21174

[44] Andrews GP, Jones DS, Abu Diak O, McCoy CP, Watts AB, McGinity JW (In press). The manufacture and characterization of hot melt extruded enteric tablets. Eur J Pharm Biopharm 2008; 69(1):264-73.

[45] Mehuys E, Remon JP, Vervaet C. Production of enteric capsules by means of hot-melt extrusion. Eur J Pharm Sci 2005; 24: 207-212.

[46] Miller DA, Jason TM, Yang W, Robert OW, McGinity JW. Hot-Melt Extrusion for Enhanced Delivery of Drug Particles. J Pharm Sci 2007, 96(2): 361-376.

[47] Verreck G, Decorte A, Heymans K, Adriaensen J, Liu D, Tomasko D, Arien A, Peeters J, Van den Mooter G, Brewster ME. Hot stage extrusion of p-amino salicylic acid with EC using CO2 as a temporary plasticizer. Int J Pharm 2006; 327: 45-50.

[48] Breitkreutz J, El-Saleh F, Kiera C, Kleinebudde P, Wiedey W. Pediatric drug formulations of sodium benzoate: II. Coated granules with a lipophilic binder. Eur. J. Pharm. Biopham 2003; 56, pp. 255-60.

[49] Douroumis D. Practical approaches of taste masking technologies in oral solid forms. Expert Opin. Drug Deliv 2007; 4 , pp. 417-426.

[50] Douroumis D. Orally disintegrating dosage forms and taste-masking technologies. Expert Opin Drug Deliv 2010; 8, pp. 665-75.

[51] Breitkreutz J, El Saleh F, Kiera C, Kleinebudde P, Wiedey W. Pediatric drug formulations of sodium benzoate II. Coated granules with a lipophilic binder. Eur. J. Pharm. Biopharm. 2003, 56: 255-260.

[52] Vaassena J, Bartscherb K, Breitkreutza J. Taste masked lipid pellets with enhanced release of hydrophobic active Ingredient. Int. J. Pharm 2012, 429:99- 103.

[53] Gutierrez-Rocca JC, McGinity JW. Influence of aging on the physical-mechanical properties of acrylic resin films cast from aqueous dispersions and organic solutions. Drug Development and Industrial Pharmacy 1993, 19:315-332.

[54] Steuernagel CR. Latex emulsions for controlled drug delivery. In McGinity JW. (Ed.), Aqueous polymeric coatings for pharmaceutical dosage forms (Vol. 79, pp. 582). New York: Marcel Dekker Inc.1997

[55] Barnhart S, Thin film oral dosage forms, in: Rathbone MJ, Hadgraft J, Roberts MS, Lane ME (Eds.), Modified-release Drug Delivery Technology, Informa Healthcare, 2008:209_ 216.

[56] International Conference on Harmonization, ICH topic Q3C(R3) Impurities: Residual Solvents, 2009.

$<$ http://www.emea.europa.eu/pdfs/human/ich/028395en.pdf $>$.

[57] Morales JO, McConvill JT. Manufacture and characterization of mucoadhesive buccal films. Eur J Pharm Biopharm.2011, 77:187-99. 
[58] Repka MA, McGinity JW, Zhang F, Koleng JJ. Encyclopedia of pharmaceutical technology, in: J. Boylan (ed.), Marcel Dekker, NewYork, 2002.

[59] Venkat S. Tumuluri, Mark S. Kemper, Ian R. Lewis, Suneela Prodduturi, ${ }^{c}$ Soumyajit Majumdar, Bonnie A. Avery, and Michael A. Repka Off-line and On-line Measurements of Drug-loaded Hot-Melt Extruded Films Using Raman Spectroscopy.

[60] Mididoddi PK, Repka MA. Characterization of hot-melt extruded drug delivery systems for onychomycosis. Eur J Pharm Biopharm. 2007, 66:95-105.

[61] Prodduturi S, Manek R, Kolling W, Stodghill S, Repka M. Solid-state stability and characterization of hot-melt extruded poly(ethylene oxide) films, Journal of Pharmaceutical Sciences 2005; 94:2232-2245.

[62] Repka M, Gutta K, Prodduturi S, Munjal M, Stodghill S. Characterization of cellulosic hot-melt extruded films containing lidocaine, European Journal of Pharmaceutics and Biopharmaceutics 2005; 59:189-196.

[63] Repka M, McGinity J. Bioadhesive properties of hydroxypropylcellulose topical films produced by hot-melt extrusion, Journal of Controlled Release 2001; 70:341-351.

[64] Thumma S, Majumdar S, ElSohly M, Gul W, Repka M. Preformulation studies of a prodrug of D9-tetrahydrocannabinol, AAPS Pharmaceutical Science and Technology 2008a; 9:982-990.

[65] Repka M, Gerding T, Repka S, McGinity J. Influence of plasticizers and drugs on the physical-mechanical properties of hydroxypropylcellulose films prepared by hot melt extrusion, Drug Development and Industrial Pharmacy 1999; 25:625-633.

[66] Prodduturi S, Manek R, Kolling W, Stodghill S, Repka M. Water vapour sorption of hot-melt extruded hydroxypropyl cellulose films: effect on physico-mechanical properties, release characteristics, and stability, Journal of Pharmaceutical Sciences 2004; 93: 3047-3056.

[67] Kopcha M, Tojo KJ, Lordi NG. Evaluation of methodology for assessing release characteristics of thermosoftening vehicles, Journal of Pharmacy and Pharmacology 1990; 42: 745-751.

[68] Thumma S, ElSohly M, Zhang S, Gul W, Repka M. Influence of plasticizers on the stability and release of a prodrug of [Delta]9-tetrahydrocannabinol incorporated in poly (ethylene oxide) matrices, European Journal of Pharmaceutics and Biopharmaceutics 2008b; 70 :605-614.

[69] Crowley MM., Zhang F, Repka MA, Thumma S, Upadhye SB, Battu SK, McGinity J, Martin C. Pharmaceutical Applications of Hot- Melt Extrusion: Part I. Drug Development and Industrial Pharmacy 2007; 33: 909-926.

[70] Klein CE, Chiu Y, Awni W, Zhu T, Heuser RS, Doan T, Breitenbach J, Morris JB, Brun SC, Hanna GJ. The tablet formulation of lopinavir/ritonavir provides similar bioavailability to the soft-gelatin capsule formulation with less pharmacokinetic variability and diminished food effect. J Acquir Immune Defic Syndr 2007; 44: 401-410. 